\title{
MODELING THE CHOICE BETWEEN REGULATION AND LIABILITY IN TERMS OF SOCIAL WELFARE ${ }^{1}$
}

\author{
by \\ MARCEL BOYER \\ Department of Economics and CIRANO, \\ Université de Montréal, Canada. \\ (marcel.boyer@umontreal.ca) \\ and \\ DONATELLA PORRINI \\ Istituto di Scienze Economiche e Statistiche, \\ Università degli Studi di Milano, Italy. \\ (donatella.porrini@unimib.it)
}

\footnotetext{
1 We thank Marc Deschamps for his comments as well as participants in meetings of the American Law and Economics Association (Washington), Canadian Law and Economics Association Meetings (Toronto), in the Workshop in Law and Economics of Environmental Policy (University College London) and in the European Association of Law and Economics (Athens) for their comments on an earlier draft of this paper.
} 


\begin{abstract}
$\underline{\text { Abstract }}$
Using a formal political economy model with asymmetric information, we illustrate the conditions under which an environmental protection system based on extending liability to private financiers is welfare superior, inferior or equivalent to a system based on an incentive regulatory scheme subject to capture by the regulatees. We explicitly consider the following factors: the cost of care and its efficiency in reducing the probability of an environmental accident, the social cost of public funds, the net profitability of the risky activities, the level of damages, and the regulatory capture bias. We characterize in such a parameter space the regions where one system dominates the other.
\end{abstract}

Keywords: Environment, extended liability, capture, choice of instruments.

J.E.L. Classification numbers: D82, G32, K13, K32, L51. 


\section{Introduction}

The increasing importance of better understanding the choice between environmental policy instruments in a political economy context comes from different sources: the increasing diffusion of risky activities in modern industrial societies, the necessity to properly compensate the victims of accidents, the need to induce an efficient level of care by the potential injurers in contexts characterized by asymmetric information, and the increasingly stringent budgetary limits of cash-constrained governments. ${ }^{1}$ Moreover, the topic is particularly timely because of the challenging attempt to design and implement a common environmental protection system for EC countries ${ }^{2}$ and given the experience and jurisprudence under the CERCLA ${ }^{3}$ liability in the US as well as the new regulation approach adopted by the US Environmental Protection Agency (EPA).

The choice of instruments deals in general with, on the one hand, ex ante policies that regulate the risky activities of firms before an accident occurs and, on the other hand, ex post policies that control the effects of an accident and provide a set of rules to be applied once an accident has occurred. One finds in the first class, safety standards, technological standards, Pigouvian taxes, and marketable permits and in the second class, emergency civil protection plans as well as liability systems for clean-up costs and for the compensation of victims. The two types of policies create different incentives for precautionary care and involve different costs.

In this paper, we compare two broad stylized instruments: first, an assignment of strict liability on the responsible party and second, a system of regulation rules and procedures enacted by an environmental protection authority. In the first case, we consider the possibility of extending liability to the financial partners of the firm in order to address the problem of limited liability or judgment proofness ${ }^{4}$ while in the second case, we consider the possibility of capture of the

\footnotetext{
${ }^{1}$ See for instance Menell (1991), Hahn (1993), Lewis (1996) and Segerson (1996). See also Boyer, Lewis and Liu (2000) for a model where standards are set to induce proper behavior by injurers and enforcers.

${ }^{2}$ See The White Paper on Environmental Liability, COM 66 final, Bruxelles, 9 February 2000. See also Arcuri (2002).

${ }^{3}$ The Comprehensive Environmental Response, Compensation and Liability Act of 1980, 1985, 1996.

${ }^{4}$ See Summers (1983) and Shavell (1986). Regarding the relationship between regulation, judgment proofness and tort law, see De Geest and Dari Mattiacci (2002).
} 
environmental protection agency by the regulated firms.

We develop a model that integrates the following factors to compare the social efficiency of the two different regimes: the differential cost between low and high levels of environmental protection activities; the unobservability of those care levels; the social cost of public funds due to distortionary taxation; the (net) profitability of the firm, assumed to be always positive when the level of environmental protection activities is high and to be positive or negative when the level of environmental protection activities is low; the level of damages due to an accident; and finally the importance of the bias due to regulatory capture.

The model is based on the stylized features of a liability system, extended to lenders or covered by full insurance contracts, and of an incentive regulation system subject to capture. In both cases, the informational problems between parties are present. In this incomplete information political economy environment, we characterize the conditions under which incentive regulation is superior to extended liability in terms of social welfare, in particular in terms of the level of precautionary activities and of the level of investment in environmentally risky businesses.

We consider combinations of the above factors or parameters and we characterize their interactions in determining which regime, the extended liability regime or the regulation subject to capture regime, is likely to be more efficient in implementing the social welfare maximizing environmental protection policy. We compare three institutional contexts. In the first context, a benevolent regulator maximizes the proper social welfare function (the benchmark case). In the second context, a private financier, that is an insurer or a banker, maximizes her own profit but is subject to extended liability if and when a firm she finances goes bankrupt following an environmental accident. In the third context, a captured regulator, who benefits from the firm's informational rent or profit through bribes, perks and/or future employment opportunities, is biased in her maximization of the social welfare function. In all three settings, the regulator or financier can determine both the level of accident preventing care to be implemented by submitting the firm to an incentive contract, and whether or not the environmentally risky firm should be allowed or not to operate or be financed. We develop the analysis by deriving and discussing comparative statics results that we illustrate through a set of figures. 
The paper is organized as follows. In the next section, we cover some of the main contributions to the liability versus regulation literature. Section 3 is devoted to the presentation and justification of the model and to the characterization of the three solutions we want to compare. In section 4, we present the comparative statics results illustrated on different graphs, and we conclude with a capsule of the main results and some general remarks.

\section{Liability versus regulation}

The problem of the choice of instruments, such as ex ante regulation and ex post liability, has been frequently addressed in the law and economics literature. A first debate related to this issue includes non technical contributions focusing on the general problem of finding the best policy to achieve given environmental policy targets. These contributions are based on a complete information framework where imperfections are considered as reasons to prefer one instrument to the other. ${ }^{5}$ A second body of literature deals with the characterization of the relationship between the two instruments, as complements or substitutes in providing incentives to reduce the level of risk.

One of the main contributions is Shavell (1984b) showing that neither regulation nor liability leads the parties to exercise the socially desirable level of care. This is due to different factors: on the one hand, the regulatory authorities suffer from lack of information problems and, on the other hand, a liability system presents the possibility that the parties would not pay fully for harm and might not even be sued. Shavell first of all considers the case where only the liability system or the regulation system can be used and then the case where both systems can be used jointly so that the parties must satisfy regulatory standards and are also subject to liability. He concludes that it is generally socially advantageous to use both liability and regulation because, in those cases, the regulatory standard can be lower than if regulation is used alone: liability improves the efficiency of the regulatory system.

In another contribution, Kolstad, Ulen and Johnson (1999) stress that the two policies may

\footnotetext{
${ }^{5}$ Calabresi (1970); Weitzman (1974); Wittman (1977).
} 
be complementary. They claim that even if the phenomenon of complementary use of ex ante and ex post instruments is widespread, the economic literature has mainly studied the two separately, characterizing each of them by different inefficiencies. In addition to the four sources of inefficiencies considered by Shavell, namely the positive probability that the suit will never be brought against the injurer, the limited resources of the injurer to pay for the damages, the imperfect knowledge of the regulatory authorities regarding the magnitude of the damage, and the setting of one single level of care for all injurers, the authors consider the imperfection in the definition of legal standards which may lead the firms to choose a level of precaution different from the socially optimal one. They conclude that the liability system, applied jointly with ex ante regulation, can correct the above inefficiencies, at least in part.

In a recent paper, Schmitz (2000) criticizes the above papers which concluded in favor of a complementary use of both ex ante regulation and ex post liability. He claims that although the liability instrument suffers from the courts' uncertain behavior, it is not clear why liability should be used at all given that regulation by itself can always implement socially optimal behavior. In Shavell (1984b), liability suffers from the injurers' limited wealth while regulation suffers from the application of the same regulatory standard to all injurers. His suggestion to use liability and regulation as complementary instruments derives from the limited efficiency of liability due to enforcement errors and to injurers escaping suits. Schmitz, using a model closely related to Shavell's, shows that if injurers cannot escape suit and if the magnitude of liability is set at the optimal level, it can never be socially advantageous to employ both liability and regulation as complementary instruments if all injurers face the same wealth constraints. But the joint use of liability and safety regulation can be valuable if wealth varies among injurers and in the latter case, the regulatory standard can be set at a level that is lower than the one corresponding to the social optimum obtained when regulation is used alone.

The specific purpose of this paper is to pursue the comparison between those imperfect instruments through a formal model of the way by which the imperfections affect the outcome: the extension of liability to private financiers is imperfect insofar as the private financier maximizes its own profit rather than social welfare; the regulatory authorities may be captured by 
the parties who may cause environmental accidents; an asymmetric information framework is considered where the level of precautionary activities is private information of the firm.

\section{Modeling and characterizing the choice of instruments}

The model is designed to compare two regimes. In the first regime, the firm interacts with a private financier who, under an extended liability regime, is the residual liable party for the environmental damages above the value of the firm's assets. The financier is assumed to be a deep pocket institution (with a non-binding limited liability) which maximizes its own profit when dealing with the firm. ${ }^{6}$ In the second regime, the firm interacts with a regulator who is responsible for implementing environmental protection policies regarding both the accident preventing effort level and whether the firm should be allowed to operate or not, so in a sense should be financed of not. ${ }^{7}$ The regulator maximizes welfare but may be subject to a form of capture by the regulated firm. Under this regulatory regime, the regulator takes into account the fact that the latter must be financially viable and that financial contracts have significant impacts on the firm's incentives to exert a high level of accident preventing activities.

We want to concentrate here on the difficulty for regulators and financiers to directly observe the accident preventing activities of firms. This relative difficulty to observe the way firms choose to prevent the occurrence of catastrophic accidents is a significant and realistic characteristic of the challenging task of designing efficient policies for proper environmental protection. Quite often, the prevention and contingency plans are public and/or observable by concerned parties but the daily implementation of those plans is not. This unobservability of the implementation of prevention and contingency plans is a major source of information asymmetries between the external stakeholders and the firm managers or owners. This asymmetry imposes significant constraints on the design and implementation of environmental policies. If those constraints

\footnotetext{
${ }^{6}$ Many authors have considered the topic of extended liability for environmental accidents. See among others Pitchford (1995 and 2001), Heyes (1996), Boyer and Laffont (1996 and 1997), Boyd and Ingberman (1997), Boyer and Porrini (2001 and 2002), Lewis and Sappington (1999 and 2001), Balkenberg (2001), Porrini (2001).

${ }^{7}$ For simplicity, we assume a direct financial link between the regulator and the firm, as a reduced form representation of the structural relationships between the regulator, the firm and the financial markets. See among others Hahn (1990), Laffont (1995), Boyer and Laffont (1997).
} 
are not adequately taken into consideration, the policies will turn out to be socially too costly and/or inefficient, and therefore unable to achieve the objectives pursued.

To take into account this environmental protection feature, we consider the following information structure: the realized profit level is assumed to be observable by everyone while the level of accident prevention care is assumed to be a private information of the firm and therefore observable neither by the regulator nor by the private financier. The relationships between the regulator and the firm and between the private financier and the firm are modeled in a principalagent framework. The timing of the interplay between the principal (either the public regulator or the private financier) and the firm is modeled as follows in both regimes considered. The principal offers the firm a financial contract that explicitly identifies the payments to be made if the firm is financed; since the level of profit is observable but the level of accident preventing activities is not, the payments made by the firm will optimally depend on the level of profits ${ }^{8}$ but not on the level of accident preventing activities. The firm then chooses its level of care and produces. Profits are then observed and an environmental accident occurs or not.

The firm needs to borrow $I$ to operate. The firm's operations are assumed to generate either a low level of net income $\underline{\pi}$ or a high one $\bar{\pi}$ with probability $p$ and $1-p$ respectively, the expected net income (before accounting for the expected cost of an accident and the cost of care) being $\Pi=p \underline{\pi}+(1-p) \bar{\pi}$. The firm's operations are risky and can cause an accident with damage $d$ which would make the firm bankrupt, $d>\bar{\pi}$. The probability of such an accident depends on the firm's accident preventing activities. For matter of simplicity, we assume that the probability of an accident is equal to $1-a$ where $a$ is the level of accident preventing activities which can be chosen to be high $\bar{a}$ or low $\underline{a}$, both levels being normalized to the interval $(0,1)$. We denote the differential cost between the high and low levels as $\Delta$ and normalize the cost of the low level $\underline{a}$ at 0 . We assume that the differential cost $\Delta$ and the efficiency of care in reducing the probability of an accident, namely $(1-\underline{a})-(1-\bar{a})=(\bar{a}-\underline{a})$, are such that it is socially optimal in a full information first best sense that a high level of care be exerted by the firm, that is $\Delta<(\bar{a}-\underline{a}) d$.

We characterize and compare three solutions. The benchmark solution corresponds to the case

\footnotetext{
${ }^{8}$ Hence the financial contract will not be a standard loan contract.
} 
where a benevolent regulator, not subject to capture, decides whether or not the firm should operate, that is be financed or not, and directly chooses the financial contract offered to the firm in order to maximize a utilitarian social welfare function in which the informational rent of the firm is properly accounted for. ${ }^{9}$ The second solution is obtained when the decision whether the firm should operate or not is delegated to a private financier who, under an extended lender liability, decides to finance the firm or not and to offer a financial contract that maximizes her own expected profit function in which the informational rent of the firm is not present. The third solution is obtained when the captured regulator decides whether the firm should operate or not and chooses the financial contract offered to the firm; the captured regulator maximizes a distorted social welfare function in which the informational rent of the firm is overvalued.

The utilitarian social welfare function we use contains three terms: a first term corresponds to the expected net observable benefits of the firm's activities or project; a second term corresponds to the expected cost of an accident (probability of accident times the amount of damage); a third element corresponds to the informational rent or supra competitive profit that comes from the assumption that the level of the firm's chosen precautionary activities is not observable. This rent is positive only if a high level of care is induced.

If the net social value of inducing a high level of care is low enough, then it may be better from a social point of view not to induce a high level of accident preventing activities, and therefore to tolerate a higher probability of accident, in order to avoid granting the firm an informational rent that may be socially costly. Indeed, we assume the existence of a social cost of public funds $\lambda$ due to distortionary taxation in the economy. ${ }^{10}$ Since the profit of the firm is observable, it could be used to reduce the general distortionary taxes. The profit thus enters the social welfare function with a weight of $(1+\lambda)$ to explicitly represent its potential social value. Similarly, the expected cost of an accident enters the social welfare function with a weight of $(1+\lambda)$ because the government will have to cover that cost one way or another, either directly

\footnotetext{
${ }^{9}$ As mentioned above, this is meant to be a reduced form representation of the complex relationships between the regulator, the firm and the financial markets.

${ }^{10}$ There is a large literature on this complex problem. Among others, Pigou (1947), Stiglitz and Dasgupta (1971), Kaplow (1996). Jones, Tandon and Vogelsang (1990) derive estimates indicating that $\lambda$ is of the order of 0.3 in developed countries and higher in developing ones.
} 
or through the taxation rules (tax deductible expenses for cleaning up the polluted areas and/or for compensating the victims, for instance). The existence of a social cost of public funds is an important and realistic feature of regulatory frameworks and social welfare accounting: as we will see, it will lead under some conditions to distortions in the accident preventing effort levels and to distortions also in the decision to finance or not to finance the firm's risky activities. Finally, the informational rent that the firm can capture or hide cannot be used to reduce distortionary taxation because it is not observed; it will thus enter the social welfare function with a weight of 1 to properly represent its utilitarian private value. The different regimes we consider differ in their treatment of this rent: its welfare weight is respectively 1,0 and $K>1$ for the benevolent regulator, the private financier and the captured regulator.

In a complete information context, the first best solution is feasible. It entails a high level of precautionary activities and the financing of the firm's risky activities under the condition that, given the high level of effort, the expected net income minus the fixed investment cost, the expected cost of the accident and the cost of accident preventing activities, is positive or at least non-negative, a condition that is met by assumption. This full information first best solution is achieved if we have a benevolent regulator or a captured regulator because they implement the same solution (since, even if the two regulators differ by their treatment of the firm's informational rent, the rent is zero under full information). For the same reason, the full information first best allocation is also achieved with the extended lender liability regime since it makes the financier internalize the full expected cost of an accident.

Under an asymmetric information structure and with limited liability of the firm, the internalization of externalities becomes a more difficult problem. The social optimum corresponds to the maximization of the social welfare function under the following conditions or constraints: the incentive compatibility constraint implying that, if the firm is induced to choose a high level of precautions, a costly rent is left to the firm; the limited liability of the firm requiring that the repayment levels not exceed the corresponding profit levels; the individual rationality constraint of the privately informed firm stating that the firm's expected profit cannot be negative. Under limited liability, if the accident occurs, the firm will be judgment-proof for damages above its 
profit level, so that the firm's behavior cannot simply and costlessly be controlled by imposing appropriate penalties.

The model is a bare-bone model through which one can analyze the complex issues related to the comparison between liability and regulation. The capacity of the regulator to implement the first best solution is impaired by the unobservability of accident preventing care. Similarly, the extension of liability to private financiers has a long tradition, especially in the US under CERCLA. Also, the possibility of capture of regulators by regulated firms is well documented. Finally, distribution and efficiency issues are linked through the social cost of public funds, making it imperative to minimize the extra rents a firm can capture under asymmetric information. All these realistic features are contained in our model of instrument choice.

Incentive compatibility requires that the firm gains in exerting a high level of care. Letting $\bar{P}[\underline{P}]$ be the payment to be made if profit is high $[\mathrm{low}]$ and $E P$ be the expected payment, this implies that $(\bar{a})(\Pi-E P)-\Delta \geq(\underline{a})(\Pi-E P)$ implying that the expected payment be at most equal to $\Pi-\Delta /(\bar{a}-\underline{a})$. Substituting this value in the profit function under $\bar{a}$, we obtain $(\bar{a})(\Pi-E P)-\Delta=\bar{a} \Pi-\bar{a}(\Pi-\Delta /(\bar{a}-\underline{a}))-\Delta$. That is, to be induced to exert a high level of care, the firm must be granted a rent $\mathcal{R}$ equal to its expected (supra competitive) profit when it is induced to exert a high level of care:

$$
\mathcal{R}=\frac{\underline{a}}{\bar{a}-\underline{a}} \Delta
$$

Because of the social cost of public funds, it will be welfare enhancing to make this rent as small as possible by adjusting the payments stipulated in the financial contract so that the rent is minimized under the condition that the contract induces a high level of care. Given the nonobservability of precautionary activities, the social optimum, corresponding to the benevolent regulator solution, calls for a high level of accident preventing activities if and only if the sum of the net social cost of the firm's informational rent plus the differential cost of precautionary activities is less than or equal to the difference in the expected cost of an accident under the high and the low levels of precautionary activities, that is if and only if

$$
(1+\lambda) \mathcal{R}-\mathcal{R}+(1+\lambda) \Delta \leq(1+\lambda)(\bar{a}-\underline{a}) d .
$$


which can be rewritten as $\Delta \leq(\underline{a}-\bar{a}) d-\lambda \mathcal{R} /(1+\lambda)$, that is

$$
\Delta \leq \frac{1+\lambda}{1+2 \lambda-\lambda \underline{a}}(\bar{a}-\underline{a}) d .
$$

Financing occurs if the net social value of the firm's operations under full information is larger than the net social cost of the firm's informational rent, that is if

$$
(1+\lambda)[\Pi-I-(1-\bar{a}) d-\Delta] \geq[(1+\lambda) \mathcal{R}-\mathcal{R}]
$$

which can be rewritten as

$$
\Delta \leq \frac{(1+\lambda) \bar{a}-\underline{a}}{(1+\lambda)(\bar{a}-\underline{a})}[\Pi-I-(1-\bar{a}) d]
$$

Otherwise, it is best that the firm exerts a low care level (with no rent), in which case it should be allowed to operate if and only if

$$
(1+\lambda)[\Pi-I-(1-\underline{a}) d] \geq 0 .
$$

This "social optimum under moral hazard" financing rule differs from the first best full information rule because of the presence of the informational rent to be given up to the firm when the benevolent regulator wants to induce a high level of care. ${ }^{11}$ The benevolent regulator cannot avoid giving up that rent to induce a high level of care and will therefore take into account the net social cost of that rent in deciding if the firm should be allowed to operate or not and in deciding what level of accident preventing activities should be implemented. If the net social cost of the rent is large, the benevolent regulator may prefer, in maximizing social welfare, to induce a low level of accident preventing activities, thereby generating a high probability of environmental accidents. It may even turn out that the benevolent regulator will prevent the firm from operating even if the firm's activities or projects are socially valuable under full information.

Under an extended lender liability regime, the principal is a private financier. As in the benevolent regulator case, the full expected cost of an accident is properly internalized given that the financier is the residual claimant of that cost. The difference is in the treatment of the firm's informational rent, which as before appears only when the high level of effort is induced. Hence,

\footnotetext{
${ }^{11}$ In the first best full information context, the condition for financing the firm would be: if the net social value of the firm's operations under full information is larger than 0 .
} 
the comparison between the two regimes rests on their different evaluation of the firm's rent when a high level of care is induced. For the private financier, the cost of the rent is equal to the amount of the rent itself while for the benevolent regulator the net cost is smaller because she considers the private value of that rent in the social welfare function. The private financier, under extended liability, will induce the firm to exert a high level of accident preventing activities if and only if

$$
\mathcal{R}+\Delta \leq(\bar{a}-\underline{a}) d
$$

which can be rewritten as

$$
\Delta \leq \frac{(\bar{a}-\underline{a})^{2}}{\bar{a}} d
$$

She will then finance the firm if and only if

$$
\Pi-I-(1-\bar{a}) d-\Delta \geq \mathcal{R}
$$

which can be rewritten as

$$
\Delta \leq \frac{\bar{a}-\underline{a}}{2 \bar{a}-\underline{a}}[\Pi-I-(1-\bar{a}) d]
$$

Otherwise, she prefers that the firm exerts a low care level (with no rent) and will then finance the firm if and only if (3) is satisfied. This implies that the private financier is less willing than the benevolent regulator to lend and to induce a high level of accident preventing activities. Hence this undervaluation of the social value (overvaluation of its cost) of the firm's unavoidable informational rent leads to insufficient financing and too little care activities as compared with the solution a benevolent regulator would choose to implement. If the financier chooses to let the firm exert a low level of care in preventing accidents, there will be no rent and therefore the bank lends as often as the benevolent regulator would in that case. Hence, an extended lender liability regime will generate a welfare cost because of insufficient financing of risky business and because of infrequent inducement of high care levels.

The captured regulator overvalues the firm's informational rent in her version of the social welfare function, due to her indirect interests in the firm's informational rent or profit. Instead of evaluating the firm's rent at its face value $\mathcal{R}$, she values it at $K \mathcal{R}$ with $K>1$. Because this informational rent is obtained by the firm only when it is induced to choose the high level of 
accident preventing activities, the captured regulator induces a high level of accident preventing activities more often than the benevolent regulator does. Indeed, the maximization of the biased social welfare function calls for a high level of accident preventing activities if and only if the biased net social cost of the firm's informational rent plus the differential cost of precautionary activities is less than or equal to the difference in the expected cost of an accident under the high and the low levels of precautionary activities, that is if and only if

$$
(1+\lambda) \mathcal{R}-K \mathcal{R}+(1+\lambda) \Delta \leq(1+\lambda)(\bar{a}-\underline{a}) d
$$

which can be rewritten as

$$
\Delta \leq \frac{(1+\lambda)(\bar{a}-\underline{a})^{2}}{(1+\lambda)(2 \bar{a}-\underline{a})-K \bar{a}} d
$$

When she induces a high level of care conceding a rent to the firm, she also lends more often than called for by the second best optimal investment rule again because she overvalues the firm's rent or profit in her objective function. Indeed, financing occurs then if the net social value of the firm's operations under full information is larger than the biased net social cost of the firm's informational rent, that is if

$$
(1+\lambda)[\Pi-I-(1-\bar{a}) d-\Delta] \geq[(1+\lambda) \mathcal{R}-\mathcal{K} \mathcal{R}]
$$

which can be rewritten as

$$
\Delta \leq \frac{(1+\lambda)(\bar{a}-\underline{a})}{(1+\lambda)(2 \bar{a}-\underline{a})-K \bar{a}}[\Pi-I-(1-\bar{a}) d]
$$

Otherwise, she prefers that the firm exert a low care level (with no rent) and will then let the firm operate if and only if (3) is satisfied. The net social cost of the firm's informational rent or supra competitive profit is undervalued by the captured regulator and therefore, the capture of the regulator leads to too much care and to overinvestment in the case of a high level of care as compared with the solution a benevolent regulator would choose to implement. When a low level of care is induced, then no rent is left to the firm and the investment rules of the captured regulator and the benevolent regulator are the same. Hence, a regulation subject to capture regime will generate a welfare cost because it leads to excessive financing of risky activities and to too frequent inducing of high levels of accident preventing activities. 


\section{The impact of changes in parameter values on the choice of regimes}

We can compare the two regimes considered, the extended liability regime and the regulation subject to capture regime, by referring to five illustrative figures. In the captions of those figures, BR stands for the solution (the investment rule, that is allowing the firm to operate or not, and the level of accident preventing activities) implemented by the "benevolent regulator", CR stands for the solution implemented by the "captured regulator" and PF stands for the solution implemented by the "private financier". We use " " to mean "is equivalent to" and " $\succ$ " to mean "is preferred to". The five graphs presented here are of course only some of the graphs that can be obtained by taking any two parameters as coordinates and giving numerical values to the other parameters of the model. The graphs are illustrative of the kind of results that can be derived from a formal analysis of the choice of instruments.

In each figure, the numbers associated with the different curves correspond to the equation numbers above; we use dotted curves to indicate that the condition is ineffective for the case considered. We indicate by $\Phi_{1}$ the region, in the particular parameter space represented by the coordinates, where both the extended liability and the regulation subject to capture regime are equivalent to the benevolent regulator regime in the sense that they all induce a high level of accident preventing activities and implement the same investment or financing rule. Hence, in that region, both regimes are equivalent and generate no welfare loss. We indicate by $\Phi_{2}$ the region where again both the extended liability regime and the regulation subject to capture regime are equivalent to the benevolent regulator regime in the sense that they induce a low level of accident preventing activities and implement the same investment or financing rule. Hence, in that region, both regimes are again equivalent and generate no welfare loss.

In regions $\Omega$ and $\Gamma$, the two regimes differ, the regulation subject to capture regime being welfare superior to the extended liability regime in region $\Omega$ and welfare inferior in region $\Gamma$. In region $\Omega$, the regulation subject to capture regime is equivalent to the benevolent regulator in the sense that both induce a high level of accident preventing activities and both let the firm operate. 
Hence, in that region, the regulation subject to capture regime implements the social welfare maximizing solution and therefore generates no welfare loss. However, in that region, the firm is always financed under the extended liability regime but with a low level of accident preventing activities and therefore generates a welfare loss: there would be too many environment damaging accidents.

In region $\Gamma$, the extended liability regime is equivalent to the benevolent regulator one in the sense that both induce a low level of accident preventing activities and both let the firm operate or be financed. Hence, in that region, the extended liability regime implements the social welfare maximizing solution and therefore generates no welfare loss. However, in that region, the regulation subject to capture regime always finances the firm but it induces a high level of accident preventing activities and therefore generates a welfare loss: it would imply too few environment damaging accidents. In this region, the welfare maximizing solution calls for a low level of accident preventing care and a correspondingly high probability of accident because the social cost of the informational rent that the firm can obtain if induced to exert a high level of care is too high. It is better, from a social welfare point of view, to tolerate a higher probability of accident with no informational rent for the firm than to reduce the probability of accident together with abandoning a costly rent to the firm.

Let us consider Figure 1. The case depicted in this figure is such that the project is valuable even if the low level of accident preventing activities is exerted, that is condition (3) is satisfied. Hence the firm will always be financed or allowed to operate.

\section{Insert Figure 1 here}

Suppose that in Figure 1 the net social opportunity cost of public funds is $\lambda=0.6$. Then, as the differential cost between the high and low levels of accident preventing activities $\Delta$ increases, we go from region $\Phi_{1}$ where both regimes are equivalent and generate no welfare loss to region $\Omega$ where, once (4) is crossed, the private financier would find it unprofitable to induce the firm to exert a high level of care because with a higher $\Delta$ the rent (recall that $R=\underline{a} \Delta /(\bar{a}-\underline{a})$ ) that the firm can capture becomes too large. In spite of extended liability and therefore of 
the full internalization of the expected cost of an accident, the private financier finds it more profitable to let the probability of accident be relatively large. In that region, the regulation subject to capture is preferred. But for a larger value of $\Delta$, we move into region $\Gamma$ where the social optimum under moral hazard calls for a low level of accident preventing effort and no rent because the otherwise unavoidable rent increases with the differential cost of care. However, because the captured regulator has a vested interest in keeping the firm's rent or profit high, and since this rent is obtained only if a high level of effort is induced, she keeps inducing the firm to exert a high level of effort to reduce the probability of environmental accidents. But in so doing, she moves away from the social optimum which calls in this region $\Gamma$ for the elimination of the rent at the expense of a higher probability of accident. In that region, the investment and care policies of the private financier and of the benevolent regulator coincide and therefore the extended liability regime is preferred. As the differential cost $\Delta$ increases even more, we move into region $\Phi_{2}$ where the rent level becomes so high that both the captured regulator and the private financier opt for letting the firm operate at a low level of effort but with no rent.

Let us now suppose that the differential cost between the high and low levels of accident preventing activities $\Delta$ is fixed at the 0.5 level. As the social cost of public funds $\lambda$ increases from 0 to 1 , we move successively into regions $\Omega, \Gamma$ and $\Phi_{2}$. When the value of $\lambda$ becomes large enough to cross boundary (1) - note that this occurs earlier for larger values of $\Delta$ - the cost of the rent becomes relatively high and it is then better to opt for the private financier extended liability regime which leaves no rent to the firm: the higher probability of accident that the private financier regime would imply is better, from a social welfare point of view, than the larger rent that the captured regulator regime would allow.

Hence, Figure 1 shows that larger values of the social opportunity cost of public funds - above (1) - favor the private financier extended liability regime as the preferred instrument, while smaller values of the differential cost between the high and low levels of accident preventing activities - to the left of (1) - favor the regulation subject to capture regime as the preferred instrument to implement the socially optimal environmental policy both in terms of allowing or not allowing the firm to operate (or be financed) and in terms of the level of accident preventing 
activities.

Let us consider Figure 2. In the case depicted in this figure, we consider the same variable parameters (coordinates) as in Figure 1 and the same fixed values for the other parameters except for the probability of accident under a low level of care $\underline{a}$ which is now set at 0.3 rather than 0.1 ; this higher probability of accident when the firm exerts a low level of care implies that the firm's operations are not socially valuable under full information when the low level of accident preventing activities is exerted, hence (3) is not satisfied.

\section{Insert Figure 2 here}

We now find that in region $\hat{\Omega}$, the private financier solution calls for not financing the firm because the no rent solution with a low level of accident preventing activities is not profitable. But the social optimum under moral hazard calls for letting the firm operate and be induced to exert a high level of care. The captured regulator will implement such a solution and is therefore the preferred instrument in this region. In spite of the fact that there will be more environment damaging accidents with the captured regulator regime than with the private financier regime, it is socially optimal to face the risk of such accidents. However, as we move into region $\hat{\Gamma}$, either because of a higher level of the social cost of public funds $\lambda$ or because of a higher differential cost between the high and low levels of accident preventing activities, the social optimum is to prevent the firm from operating: the rent captured by the firm under a high level of effort is too large (higher $\Delta$ ) or too costly (higher $\lambda$ ) compared to the social value of the firm's operations. In region $\hat{\Gamma}$, the captured regulator would rather let the firm operate with a high level of effort, thereby allowing an informational rent to be captured by the firm in which she has some interest. In this region, the private financier is the preferred instrument. As in region $\hat{\Omega}$, there would be more environment damaging accidents with the captured regulator regime than with the private financier regime, but now the social cost of the unavoidable rent has become too large to make it socially profitable to face the risk of such accidents, even if reduced.

Let us suppose as before that the net social opportunity cost of public funds is $\lambda=0.6$. Then, as the differential cost between $\bar{a}$ and $\underline{a}$ goes up, we move from the region where neither the 
private financier regime nor the captured regulator regime generate any welfare loss to region $\hat{\Omega}$ where, once (5) is crossed, the private financier would find it unprofitable to finance the firm. ${ }^{12}$ In that region, the regulation subject to capture is preferred. But, for a larger discrepancy cost, we move into region $\hat{\Gamma}$ where the social optimum under moral hazard calls for not financing the firm. However, because the captured regulator has a vested interest in keeping the firm's rent or profit high, and since this rent is obtained only if a high level of effort is induced and the firm is in operation, she keeps letting the firm operate while inducing it to exert a high level of effort to reduce the probability of environmental accidents. But in so doing, she moves away from the social optimum which calls in this region $\hat{\Gamma}$ for preventing the firm from operating. In that region, the investment policies of the private financier and the benevolent regulator coincide and therefore the extended liability regime is preferred. As the differential cost increases even more, we move into region $\hat{\Phi}_{2}$ where the rent level becomes so high that both the captured regulator and the private financier opt for not financing the firm and therefore neither generates a welfare loss.

Let us now suppose that the differential cost $\Delta$ is fixed at the 2.5 level. As the social cost of public funds increases from 0 to 1 , we move successively into regions $\hat{\Omega}, \hat{\Gamma}$ and $\hat{\Phi}_{2}$. When the value of $\lambda$ becomes large enough to cross boundary (2) - note that again this occurs earlier for larger values of $\Delta$ - the cost of the rent that the captured regulator would leave to the firm by letting it operate and inducing a high level of accident preventing activities becomes too high and it is better to opt for the private financier regime which will not finance the firm at all: the no financing solution of the private financier regime is now better, from a social welfare point of view, than letting the firm operate even with a high level of accident preventing activities which the captured regulator regime would imply.

Hence, when the firm's project is socially valuable only if a high level of care is exerted, Figure

\footnotetext{
${ }^{12}$ In some cases, a partial liability system, as discussed by Boyer and Laffont (1997), may be better if there is some room to maneuver between the need to induce the private financier to monitor the firm and provide it with the incentives to exert a high level of effort and the need to finance the firm whenever it is socially valuable to do so. In Figure 2, making the private financier partially liable would move (4) to the left and (5) to the right and lead to a welfare improvement. Similarly, under a negligence rule, as discussed by Pfaff and Sanchirico (2000), the 'integrated organization', that is the private financier together with the firm, may be fined too heavily for violations of the regulations as compared to an optimal fine level which could be a decreasing function of the organization's monitoring and disclosure rules and efforts.
} 
2 shows that "higher" values of the social opportunity cost of public funds - above (2) - favor the private financier regime as the preferred instrument, while "lower" values of the differential cost between the high and low levels of accident preventing activities - to the left of $(2)$ - favor the regulation subject to capture regime as the preferred instrument to implement the socially optimal environmental policy both because it would allow the firm to operate, contrary to the private financier regime, and because it would induce the firm to choose a high level of accident preventing activities.

Let us now consider Figure 3 where the social cost of public funds is fixed at 0.3 and the variable parameters (coordinates) are now the differential cost between high and low levels of accident preventing activities as before and the cost of an accident $d$. The level of damages if an accident occurs remains fixed but we consider different levels of this fixed value between $\bar{\pi}$ and 50 . The parameter values of this case are otherwise the same as in Figure 1 and therefore the firm's operations are valuable even under a low level of care. The regions $\Phi_{1}, \Omega, \Gamma$ and $\Phi_{2}$ have the same interpretation as before: the two regimes are equivalent instruments in $\Phi_{1}$ and $\Phi_{2}$, the regulation subject to capture is preferred in region $\Omega$ and the private financier extended liability regime is preferred in region $\Gamma$. The firm is financed in all regions but the level of accident preventing activities differs between regions and regimes.

\section{Insert Figure 3 here}

Let us suppose that the differential cost between the high and low levels of care $\Delta$ is fixed at the 0.1 level. As the cost of an accident $d$ increases from 10 to 50, we move successively into regions $\Phi_{2}, \Gamma, \Omega$ and finally $\Phi_{1}$. For relatively low values of $d$, it is socially preferable to let the firm operate with a low level of accident preventing activities, the reason being that the expected cost of an accident is not high enough to justify the social cost of the informational rent if the principal wants to induce the firm to exert a high level of care. Both regimes considered implement the social optimum under moral hazard and therefore neither generates a welfare cost. When the value of $d$ becomes large enough to cross boundary (6) - note that this occurs later for larger values of $\Delta$ since a larger $\Delta$ means a larger informational rent - the expected 
cost of an accident becomes large enough for the captured regulator to prefer inducing the firm to choose a high level of care, allowing it to get an informational rent, even if the social optimum still calls for not doing so. In region $\Gamma$, the private financier remains unwilling to abandon a rent to the firm and prefers, as the benevolent regulator does, to finance the firm and face the higher (internalized) expected cost of an accident. Hence the private financier implements the socially optimal solution under moral hazard and is therefore the preferred instrument: the higher probability of accident with no informational rent is better, from a social welfare point of view, than the lower probability of accident with a positive informational rent under the captured regulator regime. As $d$ increases more and crosses boundary (1), the larger cost of an accident now justifies that the firm be induced to exert a high level of care even if that implies a positive rent or higher profit for the firm - note that this occurs later for larger values of the differential cost between the high and low levels of care. However, the private financier still prefers not to induce the firm to choose a high level of accident preventing activities and to face the higher risk of an accident for which she is the residual liable party. In region $\Omega$, the captured regulator implements the social optimum under moral hazard and is therefore the preferred instrument: the lower probability of an accident obtained in the captured regulator regime at the cost of an informational rent for the firm is better than the higher probability of accident with no rent which the private financier regime would implement. Finally, when the value of $d$ goes over boundary (4) which is also an increasing function of $\Delta$, the cost of an accident becomes high enough for both regimes to induce the firm to choose a high level of care, as the benevolent regulator does. Therefore neither regime generates a welfare loss.

Let us suppose now that the cost of an accident is fixed at 30. Then, as the differential cost between $\bar{a}$ and $\underline{a}$ goes up, we move from region $\Phi_{1}$ where both the private financier regime and the captured regulator regime induce the firm to choose a high level of care (and therefore neither generates any welfare loss) to region $\Omega$ where, once (4) is crossed, the private financier would find it unprofitable to induce a high level of care anymore because the level of rent necessary to achieve this is now too high. In that region, the regulation subject to capture is preferred. But, for a larger discrepancy cost, we move into region $\Gamma$ where the social optimum under moral hazard calls for a low level of accident preventing activities. However, because the captured 
regulator has a vested interest in keeping the firm's rent or profit high, and since this rent is obtained only if a high level of effort is induced, she keeps inducing the firm to exert a high level of effort to reduce the probability of environmental accidents. Since the investment and prevention policies of the private financier and of the benevolent regulator coincide, the extended liability regime becomes the preferred instrument. As the differential cost increases even more, we move into region $\Phi_{2}$ where the rent level becomes so high that both the captured regulator and the private financier opt for a low level of care. Therefore neither regime generates a welfare loss.

Figure 3 shows that more costly accidents favor the captured regulator regime over the private financier extended liability regime and that the level of $d$ at which the switch occurs depends on the differential cost $\Delta$ : the higher this differential cost, the higher the critical value of $d$.

Let us now consider Figure 4 where the variable parameters (coordinates) are now the social opportunity cost of public funds and the capture factor $K$. The cost of an accident is fixed at 20 and the differential cost between the high and low levels of accident preventing activities is fixed at 0.6 while the other parameters are fixed at their same levels as in Figure 3: the firm's operations are valuable under a low level of care. The regions $\Phi_{1}, \Omega, \Gamma$ and $\Phi_{2}$ have the same interpretation as before. Hence, the firm is always financed but the level of accident preventing activities differs between regions and regimes. Note however that region $\Phi_{1}$, where the firm would be induced to exert a high level of care in all regimes, is empty in Figure 4.

Insert Figure 4 here

Let us suppose that the capture factor $K$ is fixed at the 1.2 level. As the social opportunity cost of public funds $\lambda$ increases from 0 to 1 , we move successively into regions $\Omega, \Gamma$ and finally $\Phi_{2}$. For relatively low values of $\lambda$, it is socially preferable to induce the firm to choose a high level of accident preventing activities, the reason being that the social cost of the informational rent is rather small. But only the captured regulator is willing to induce the firm to behave that way. The private financier prefers the firm to operate under a low level of care because the level of rent to be abandoned to the firm is otherwise too large. Hence, the regulation 
subject to capture regime is preferred. As the value of $\lambda$ increases and crosses boundary (1), the social cost of the informational rent increases and the social optimum under moral hazard now calls for a low level of care with no rent for the firm. However, the level of $\lambda$ is still not high enough, between boundaries (1) and (6), for the captured regulator to prefer inducing the firm to choose a high level of care: the captured regulator has a vested interest in the rent of the firm and, as long as $\lambda$ is below boundary (6), the captured regulator considers the rent as not too costly. Hence, in this region, the private financier with extended liability regime is preferred: the higher probability of accident is better from a social welfare point of view than the rent the firm would be able to obtain with a high level of accident preventing activities. Finally, as $\lambda$ becomes relatively large, the social cost of the informational rent becomes too high and even the captured regulator prefers to let the firm operate with a low level of care. In region $\Phi_{2}$, both regimes considered are equivalent and there are no welfare losses with either of them. It is interesting to note that boundary (1), at which the preferred instrument switches from the regulation subject to capture one to the private financier one, is independent of the capture factor $K$ whereas boundary (6), at which the captured regulator ceases to induce the firm to choose a high level of accident preventing activities and thus again implements the social optimum under moral hazard, is increasing with $K$.

Let us now suppose that the social opportunity cost of public funds $\lambda$ is fixed at the 0.3 level. Then, as the capture factor $K$ increases from 1 to 2 , we move successively into regions $\Phi_{2}$ and $\Gamma$, the other regions of interest $\Phi_{1}$ and $\Omega$ being empty in Figure 4 . For low values of $K$, it is socially preferable to let the firm operate with a low level of accident preventing activities, the reason being that the social cost of the informational rent, which is independent of $K$, is relatively large given that $\lambda$ is at 0.3 and $\Delta$ is at the 0.6 level. Both the captured regulator and the private financier are unwilling to induce the firm to choose a high level of care and therefore neither generates a welfare loss. As the capture of the regulator becomes more important, that is as $K$ increases above boundary (6) - this happens later for larger values of $\lambda$ - we move into region $\Gamma$ where the captured regulator is now willing to induce the firm to choose a high level of effort, reducing the probability of an accident but letting the firm obtain a costly informational rent. In so doing, the captured regulator moves away from the social optimum under moral 
hazard while the private financier remains unwilling to induce a high level of care. The private financier under extended liability becomes the preferred instrument.

Let us now consider Figure 5 where the two variable parameters (coordinates) are the social opportunity cost of public funds $\lambda$ and the probability of a low level of profit $p$. The cost of an accident is fixed at 20, the differential cost between the high and low levels of accident preventing activities is fixed at 0.6 and the capture factor is fixed at 1.2 as before. The firm's operations are valuable under a low level of care if and only if the probability of the low level of profit $p$ is below 0.8 ; for $p>0.8$, condition (3) is not satisfied. Regions $\Phi_{1}$ and $\hat{\Phi}_{1}$ are empty in Figure 5 and Regions $\Omega, \Gamma$ and $\Phi_{2}$ together with $\hat{\Omega}, \hat{\Gamma}$ and $\hat{\Phi}_{2}$ have the same interpretation as before.

\section{Insert Figure 5 here}

In $\Omega$ and $\hat{\Omega}$, the regulation subject to capture regime is the preferred instrument because in this region of the parameter space the private financier prefers, if $p \leq 0.8$, to finance the firm with a low level of accident preventing activities (because otherwise the level of the informational rent is too high) or, if $p>0,8$, not to finance the firm at all. In those regions, the captured regulator implements the social optimum under moral hazard by allowing the firm to operate while inducing it to exert a high level of care. In regions $\Gamma$ and $\hat{\Gamma}$, the private financier with extended liability regime is the preferred regime because in these regions, the private financier implements the social optimum under moral hazard: either, in $\Gamma$, by financing the firm but with a low level of care, or, in $\hat{\Gamma}$, by not financing the firm. In $\Gamma$ and $\hat{\Gamma}$, the captured regulator allows the firm to operate and induces it to exert a high level of effort and in so doing moves away from the social optimum under moral hazard. In regions $\Phi_{2}$ and $\hat{\Phi}_{2}$, both regimes, the captured regulator regime and the private financier regime, implement the social optimum under moral hazard which calls in $\Phi_{2}$ for financing the firm or allowing it to operate with a low level of accident preventing activities and in $\hat{\Phi}_{2}$ for not allowing the firm to operate.

Let us suppose that the probability of a low level of profit is fixed at the 0.6 level. As the social opportunity cost of public funds $\lambda$ increases from 0 to 1 , we move successively into regions $\Omega, \Gamma$ and finally $\Phi_{2}$, a case similar to the one discussed in Figure 4 except that in the present case, 
boundary (6) is the same for all values of $p \in(0,0.8]$. Let us now suppose that the probability of a low level of profit is fixed at the 0.82 level. As the social opportunity cost of public funds $\lambda$ increases from 0 to 1 , we move successively into regions $\hat{\Omega}, \hat{\Gamma}$ and finally $\hat{\Phi}_{2}$. When the value of $\lambda$ crosses boundary (2), the firm's project ceases to be socially valuable. Under full information, the firm's operations would be socially valuable only if the firm exerts a high level of accident preventing activities but under incomplete information (moral hazard) it ceases to be socially valuable even with a high level of care because of the social cost of the unavoidable informational rent: it is then better to prevent the firm from operating, which is what the private financier would end up doing by refusing to finance the firm. However, because of her indirect interest in the firm's rent, the captured regulator would still, in region $\hat{\Gamma}$, finance the firm and induce it to exert a high level of care, thereby implementing the full information first best optimum but not the social optimum under moral hazard which calls for shutting down the firm: because of the social opportunity cost of public funds, income distribution matters and it is no longer sufficient to attain the first best. As the social opportunity cost of public funds increases above boundary (7), the captured regulator then finds the social cost of the informational rent too high and ceases to allow the firm to operate, thereby implementing, as does the private financier regime, the social optimum under moral hazard.

Let us now suppose that the social opportunity cost of public funds $\lambda$ is fixed at the 0.03 level. Then, as the probability of a low level of profit $p$ increases towards 1 , we are successively in regions $\Omega, \hat{\Omega}, \hat{\Gamma}$ and $\hat{\Phi}_{2}$. For low values of $p$, that is for a firm with a large expected profit level, it is socially preferable to let the firm operate and to induce it to choose a high level of accident preventing activities, the reason being that the social cost of the informational rent, which is independent of $p$, is relatively low given that $\lambda$ is at 0.03 and $\Delta$ is at the 0.6 level. That is the policy the captured regulator would then implement contrary to the private financier who would prefer to finance the firm with a low level of care in order to avoid paying the unavoidable rent if a high level of care is induced. Hence the captured regulator is the preferred regime. As $p$ increases, the profitability $\Pi$ of the firm decreases, and we eventually move into region $\hat{\Omega}$ where the firm's operations are socially valuable only if a high level of care is induced. Since the private financier would not finance the firm in $\hat{\Omega}$, the captured regulator who implements 
the social optimum under moral hazard is the preferred regime. When the value of $p$ crosses boundary (2), the firm ceases to be socially profitable whatever the level of care - this occurs later for smaller values of the social opportunity cost of public funds - and the social optimum calls for preventing the firm from operating. However, because of her interest in the firm's rent, the captured regulator keeps allowing the firm to operate and inducing a high level of effort, making the private financier under extended liability the preferred instrument. Eventually, as $p$ increases even more, we move into region $\hat{\Phi}_{2}$ and both regimes implement the social optimum under moral hazard, which means that the firm is not financed.

\section{Conclusion}

To compare two major instruments to achieve environmental policy objectives, we followed a formal and structured analytical approach to model the interactions between governments, firms, regulators and financiers. We considered a stylized but explicit extended liability system and modeled the relationship between the financier as a residual liable party and the firms. Moreover, the model we developed recognizes asymmetric information and regulatory capture features and the instruments compared are in that regard "realistic" instruments. We illustrated our results through different graphs allowing a more intuitive discussion of the implications of using different instruments. We showed how the cost of the accident preventing activities, the social opportunity cost of public funds, the size of the environmental damage, the bias factor in case of regulatory capture and the firm's profitability can influence the choice between ex ante policy instruments, such as a regulatory agency, and ex post policy instruments, such as a liability system.

The instruments we characterized are sophisticated versions of the statute-based regulatory schemes and tort law systems. We considered incentive regulation rather than command and control regulation to avoid giving an advantage to liability systems at the outset in terms of more adequate exploitation of the decentralized and asymmetric distribution of information. Similarly, we considered an extended liability system to avoid giving at the outset an advantage 
to the regulatory system which would otherwise be better able to internalize the judgmentproof or limited liability constraints that all policy implementation instruments must face. In practice, the sophisticated versions of the two broad types of instruments we considered may not in general be the ones used at this time in any given jurisdictions. But we nevertheless consider the exercise fruitful and useful given that more and more sophisticated instruments are likely to be implemented, whether they are related to environmental protection or not. ${ }^{13}$

We were also careful not to tilt the balance one way or another. For example, the regulatory capture process is not modeled simply as a bribe system where the regulated firms would "buy" the decisions of the regulators but rather as a tendency for regulators to be over sensitive to, that is to put too much emphasis on, the interests of regulated firms. Our captured regulator uses the proper social welfare function except for a larger weight given to the firms' rents or supra competitive profits. This overweighing of the firms' rents implies that the captured regulator will in some cases overprotect the environment in order to allow firms to capture larger informational rents. So, rather than letting the environment unprotected in order to allow firms to increase their profits, as the popular version of the capture argument suggests, our captured regulator tends to make the protection of the environment stricter because higher protection standards are conducive to higher informational rents.

We showed the following results. A relatively large cost differential between high and low levels of care, that is a high cost of accident preventing activities, favors the extended lender liability regime. In this case, the regulator subject to capture regime would end up inducing too much care, or too few environmental accidents, and allowing the financing of too much risky business, that is an overdevelopment of environmentally risky industries: the social value of the informational rents so allowed are not large enough in that case to compensate for the social cost of the extra care activities. A relatively low cost of public funds, that is a relatively efficient non-distortionary taxation system, favors the captured regulator regime. In that case, the extended lender liability regime would end up inducing too little care, or too many environmental accidents, and allowing the financing of too few risky operations, that is an underdevelopment

\footnotetext{
${ }^{13}$ See Boyer and Laffont (1999) for a theoretical model of the pros and cons of the emergence of incentive regulation in environmental policy.
} 
of environmentally risky industries. In the latter case, the benefits of a reduced expected cost of environmental accidents are not large enough to compensate for the loss of profits (informational rents) whose social cost is small when the cost of public funds is low. More costly environmental accidents favor the captured regulator regime and the critical level of that cost above which the captured regulator regime is favored depends on the differential cost between high and low prevention: the higher this differential cost, the higher that critical level. As the regulatory capture bias factor increases above a critical value which increases with the social cost of public funds, the captured regulator begins inducing the firm to choose a high level of prevention but in so doing allows the firm to obtain a costly informational rent. In such a context, the captured regulator moves away from the social optimum under moral hazard while the private financier remains unwilling to induce a high level of care. The private financier under extended liability therefore becomes the preferred instrument.

We can conclude with some general remarks. First, it is clear that choosing between a regulation framework and a legal liability framework to implement an environmental protection policy is not an easy matter. We like to think that our analysis provides some preliminary steps in determining a way to analyze such a choice. So the answer to the question regarding which instruments should be employed by the policy makers is that a case by case examination is required. But, some of the important determinants of the relative efficiency with which different policy instruments maximize social welfare function have been characterized. 


\section{References}

[1] Arcuri A. (2002), 'Controlling Environmental Risk in Europe: the Complementarity Role of an AC Environmental Laibility Regime', 01-2 Tijdschrift voor Milieu en Recht.

[2] Balkenberg, D. (2001), 'How Liable Should a Lender Be? The Case of Judgment-Proof Firms and Environmental Risks: Comment', American Economic Review 91, 731-738.

[3] Boyd J. and D. Ingberman (1997), "The Search of Deep Pocket: is "Extended Liability" Expensive Liability?', Journal of Law, Economics, and Organization 13, 233-258.

[4] Boyer M. and J.J. Laffont (1996), 'Environmental Protection, Producer Insolvency and Lender Liability', in A. Xepapadeas (ed.), Economic Policy for the Environment and Natural Resources, Edward Elgar, 1-29.

[5] Boyer M. and J.J. Laffont (1997), 'Environmental Risk and Bank Liability', European Economic Review 41, 1427-1459.

[6] Boyer M. and J.J. Laffont (1999), 'Toward a Political Theory of the Emergence of Environmental Incentive Regulation', Rand Journal of Economics 41, 137-157.

[7] Boyer M., Lewis, T.R. and W.L. Liu (2000), 'Setting Standards for Credible Compliance and Law Enforcement', Canadian Journal of Economics 33, 319-340.

[8] Boyer M. and D. Porrini (2001), 'Law versus Regulation: A Political Economy Model of Instrument Choice in Environmental Policy', chap. 12 (249-279) in A. Heyes (ed.), Law and Economics of the Environment, Edward Elgar Ltd, 409 pages.

[9] Boyer M. and D. Porrini (2002), 'The Choice of Instruments for Environmental Policy: Liability or Regulation ?', pp. 245-268 in Timothy Swanson (ed.), An Introduction to the Law and Economics of Environmental Policy: Issues in Institutional Design, Research in Law and Economics Series Vol. 20, Elsevier Science Ltd., 2002, 540 pages.

[10] Calabresi, G. (1970), The Costs of Accidents, Yale University Press. 
[11] De Geest G. and G. Dari Mattiacci (2002), 'On the Combined Use of Anti-Judgment-Proof Regulation and Tort Law', Working Paper, Economics Institute / CIAV- Utrecht University.

[12] Hahn R.W. (1990), 'The Political Economy of Environmental Regulation: Towards a Unifying Approach', Public Choice 65, 21-47.

[13] Hahn R.W. (1993), 'Comparing Environmental Markets with Standards', Canadian Journal of Economics 26, 346-354.

[14] Heyes A. (1996), 'Lender Penalty for Environmental Damage and the Equilibrium Cost of Capital', Economica 63, 311-323.

[15] Kaplow, L. (1996), 'The Optimal Supply of Public Goods and the Distortionary Cost of Taxation', National Tax Journal XLIX, 513-533.

[16] Kolstad C.D., Ulen T.S. and G.V. Johnson (1990), 'Ex Post Liability for Harm vs. Ex Ante Safety Regulation: Substitutes or Complements', American Economic Review 80, 888-901.

[17] Jones, L.P., Tandon, P. and I. Voglesang (1990), Selling Public Enterprises, MIT Press, Cambridge, 214 pages.

[18] Laffont J.J. (1995), regulation, Moral Hazard and Insurance for Environmental Risk', Journal of Public Economics 58, 319-336.

[19] Lewis T.R. (1996), 'Protecting the Environment when Costs and Benefits are Privately Known', Rand Journal of Economics 27, 819-847.

[20] Lewis T.R. and D.E.M. Sappington (1999), 'Using Decoupling and Deep Pockets to Mitigate Judgment-Proof Problems', International Review of Law and Economics 19, 275-293.

[21] Lewis T.R. and D.E.M. Sappington (2001), 'How Liable Should a Lender Be? The Case of Judgment-Proof Firms and Environmental Risks: Comment', American Economic Review 91, 724-730.

[22] Menell P.S. (1991), 'The Limitations of Legal Institutions for Addressing Environmental Risks', Journal of Economic Perspectives 5, 93-113. 
[23] Pfaff, A.S.P. and C.W. Sanchirico (2000), 'Environmental Self-Auditing: Setting the Proper Incentives for Discovery and Correction of Environmental Harm', Journal of Law, Economics, and Organization 16, 189-208.

[24] Pigou, A.C. (1947), A Study in Public Finance, London: MacMillan.

[25] Pitchford R. (1995), 'How Liable Should a Lender Be?', American Economic Review 85, 1171-1186.

[26] Pitchford R. (2001), 'How Liable Should a Lender Be? The Case of Judgment-Proof Firms and Environmental Risks: Reply', American Economic Review 91, 739-745.

[27] Porrini D. (2001), 'Economic Analysis of Liability for Environmental Accidents', Rivista Internazionale di Scienze Economiche e Commerciali (RISEC) 2, 189-218.

[28] Segerson K. (1996), 'Issues in the Choice of Environmental Instruments', in J.B. Braden, H. Folmer, T.S. Ulen (eds), Environmental Policy with Political and Economic Integration, Brookfield: Edward Elgar.

[29] Schmitz P.W. (2000), 'On the Joint Use of Liability and Safety Regulation', International Review of Law and Economics 20, 371-382.

[30] Shavell S. (1984a), 'Liability for Harms versus Regulation of Safety', Journal of Legal Studies 13, 357-374.

[31] Shavell S. (1984b), ‘A Model of the Optimal Use of Liability and Safety Regulation', Rand Journal of Economics 15, 271-280.

[32] Shavell S. (1986), 'The Judgment proof problem', International Review of Law and Economics $6,45-68$.

[33] Stiglitz, J.E. and P. Dasgupta (1971), 'Differential Taxation, Public Goods and Economic Efficiency', Review of Economic Studies 38, 151-74.

[34] Summers, J.S. (1983), 'The case of Disappearing Defendant', University of Pennsylvania Law Review 132, 145-185. 
[35] Weitzman, M.L. (1974), 'Prices versus Quantities', Review of Economic Studies 41, 447-491.

[36] Wittman, D. (1977), 'Prior Regulation vs Post Liability: The Choice between Input and Output Monitoring', Journal of Legal Studies 6, 193-212. 
FIGURE 1

$[\underline{\pi}=5, \bar{\pi}=10, p=0.5, I=5,(1-\bar{a})=0.05,(1-\underline{a})=0.1, d=20, K=1.2]$

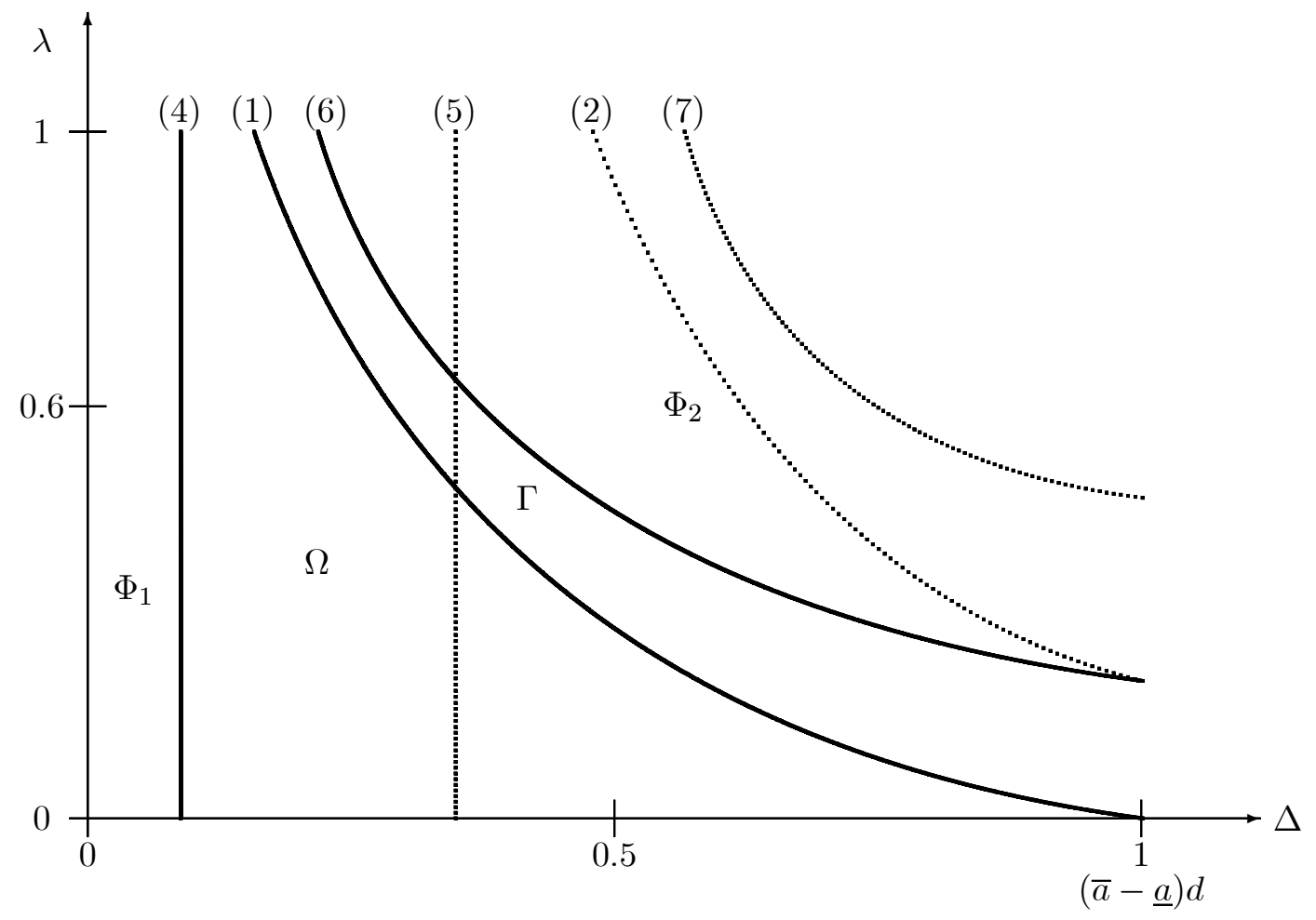

- In $\Phi_{1}, \mathrm{BR} \sim \mathrm{CR} \sim \mathrm{PF}$ with financing and $\bar{a}$

- In $\Phi_{2}, \mathrm{BR} \sim \mathrm{CR} \sim \mathrm{PF}$ with financing and $\underline{a}$

- In $\Omega, \mathrm{BR} \sim \mathrm{CR} \succ \mathrm{PF}$ with financing and $\bar{a}$ under $\mathrm{CR}$, financing and $\underline{a}$ under $\mathrm{PF}$

- In $\Gamma, \mathrm{BR} \sim \mathrm{PF} \succ \mathrm{CR}$ with financing and $\underline{a}$ under PF, financing and $\bar{a}$ under $\mathrm{CR}$ 
FIGURE 2

$[\underline{\pi}=5, \bar{\pi}=10, p=0.5, I=5,(1-\bar{a})=0.05,(1-\underline{a})=0.3, d=20, K=1.2]$

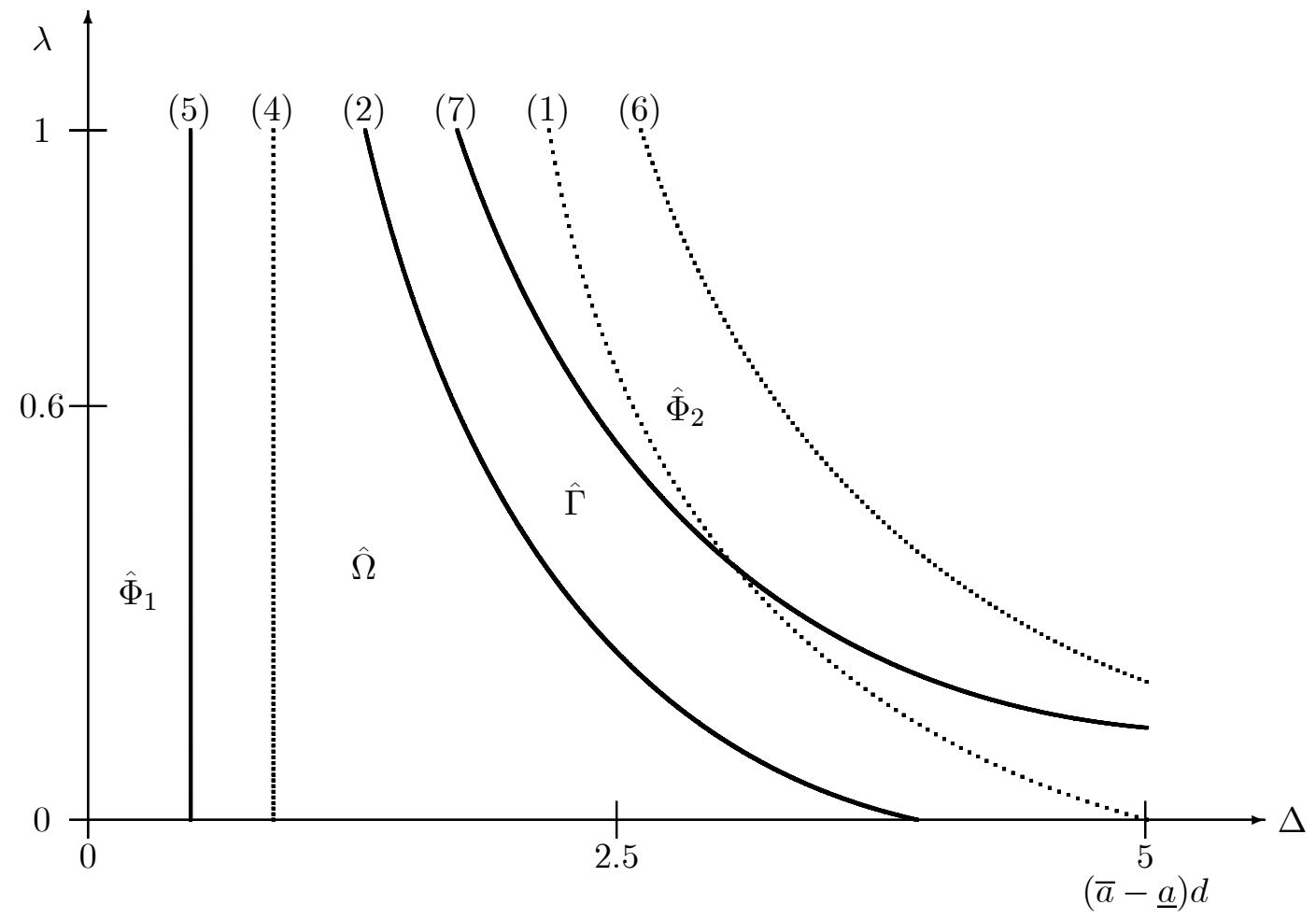

- In $\hat{\Phi}_{1}, \mathrm{BR} \sim \mathrm{CR} \sim \mathrm{PF}$ with financing and $\bar{a}$

- In $\hat{\Phi}_{2}, \mathrm{BR} \sim \mathrm{CR} \sim \mathrm{PF}$ with no financing

- In $\hat{\Omega}, \mathrm{BR} \sim \mathrm{CR} \succ \mathrm{PF}$ with financing and $\bar{a}$ under $\mathrm{CR}$, no financing under $\mathrm{PF}$

- In $\hat{\Gamma}, \mathrm{BR} \sim \mathrm{PF} \succ \mathrm{CR}$ with no financing under $\mathrm{PF}$, financing with $\bar{a}$ under $\mathrm{CR}$ 
FIGURE 3

$[\underline{\pi}=5, \bar{\pi}=10, p=0.5, I=5,(1-\bar{a})=0.05,(1-\underline{a})=0.1, K=1.2, \lambda=0.3]$

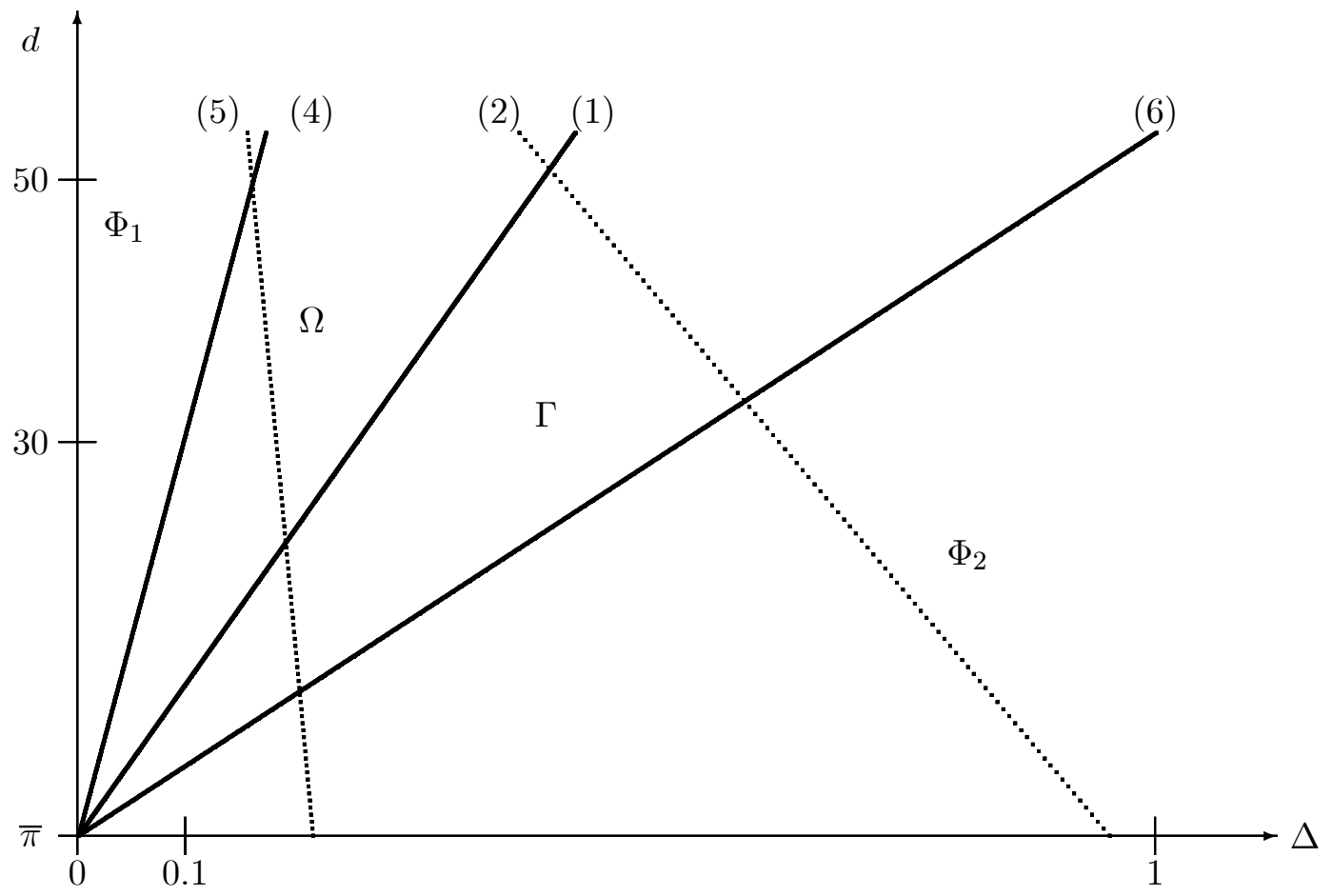

- In $\Phi_{1}, \mathrm{BR} \sim \mathrm{CR} \sim \mathrm{PF}$ with financing and $\bar{a}$

- In $\Phi_{2}, \mathrm{BR} \sim \mathrm{CR} \sim \mathrm{PF}$ with financing and $\underline{a}$

- In $\Omega, \mathrm{BR} \sim \mathrm{CR} \succ \mathrm{PF}$ with financing and $\bar{a}$ under $\mathrm{CR}$, financing and $\underline{a}$ under PF

- In $\Gamma, \mathrm{BR} \sim \mathrm{PF} \succ \mathrm{CR}$ with financing and $\underline{a}$ under PF, financing and $\bar{a}$ under $\mathrm{CR}$ 
FIGURE 4

$[\underline{\pi}=5, \bar{\pi}=10, p=0.5, I=5,(1-\bar{a})=0.05,(1-\underline{a})=0.1, d=20, \Delta=0.6]$

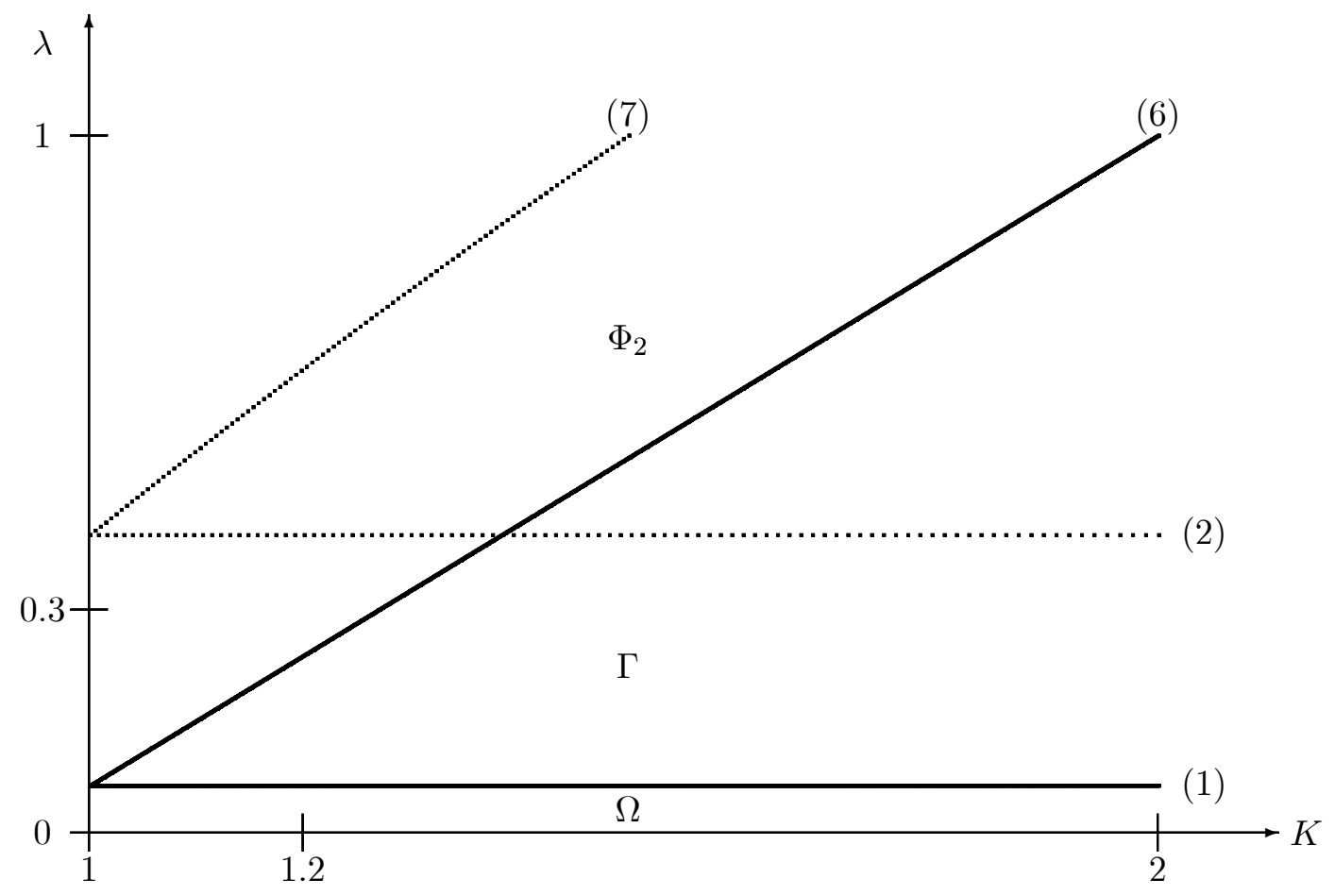

- In $\Phi_{2}, \mathrm{BR} \sim \mathrm{CR} \sim \mathrm{PF}$ with financing and $\underline{a}$

- In $\Omega, \mathrm{BR} \sim \mathrm{CR} \succ \mathrm{PF}$ with financing and $\bar{a}$ under $\mathrm{CR}$, financing and $\underline{a}$ under $\mathrm{PF}$

- In $\Gamma, \mathrm{BR} \sim \mathrm{PF} \succ \mathrm{CR}$ with financing and $\underline{a}$ under PF, financing and $\bar{a}$ under $\mathrm{CR}$ 
FIGURE 5

$[\underline{\pi}=5, \bar{\pi}=10, I=5,(1-\bar{a})=0.05,(1-\underline{a})=0.1, d=20, K=1.2, \Delta=0.6]$

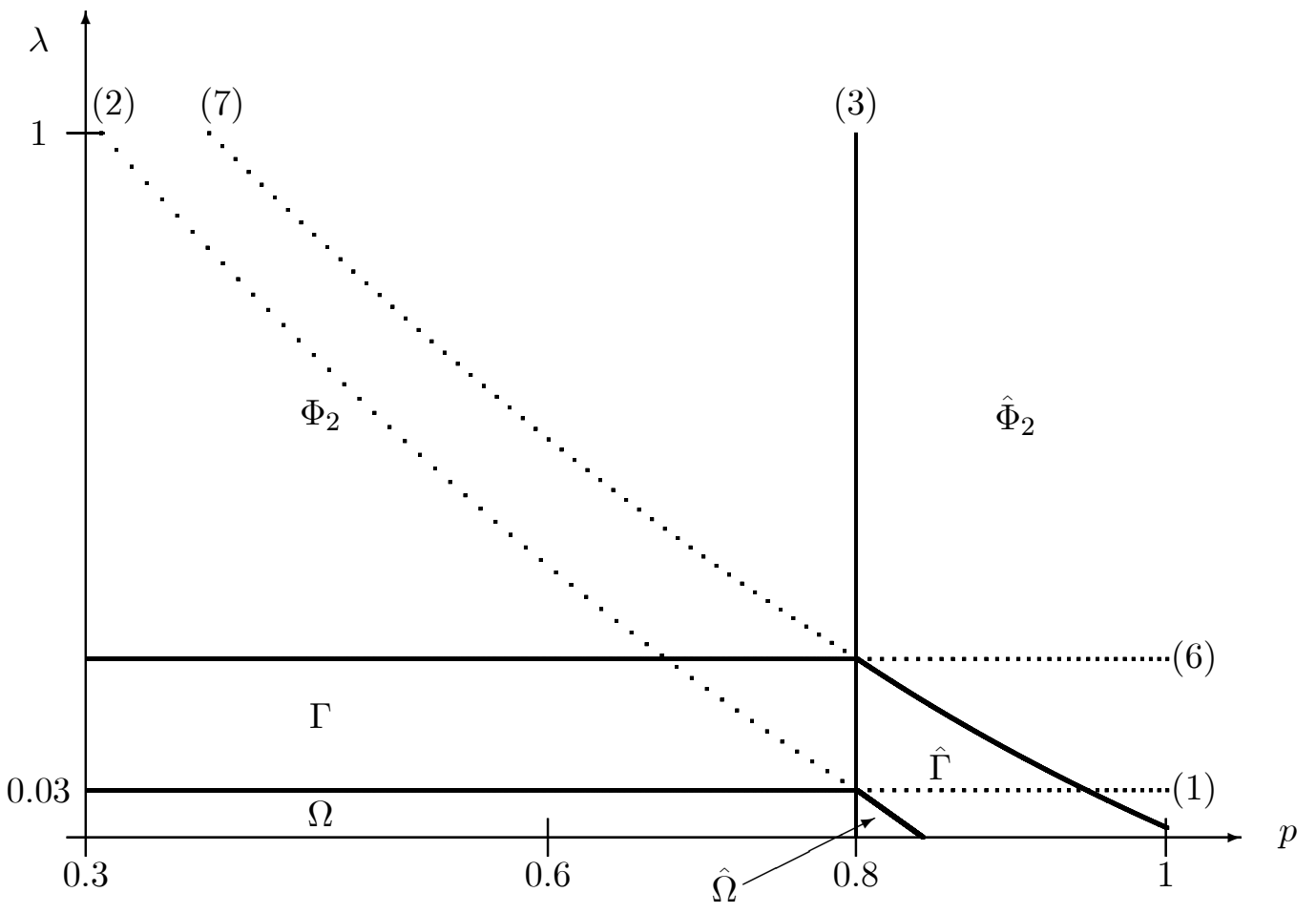

- In $\Phi_{2}, \mathrm{BR} \sim \mathrm{CR} \sim \mathrm{PF}$ with financing and $\underline{a}$

- In $\Omega, \mathrm{BR} \sim \mathrm{CR} \succ \mathrm{PF}$ with financing and $\bar{a}$ under $\mathrm{CR}$, financing and $\underline{a}$ under PF

- In $\Gamma, \mathrm{BR} \sim \mathrm{PF} \succ \mathrm{CR}$ with financing and $\underline{a}$ under PF, financing and $\bar{a}$ under $\mathrm{CR}$

- In $\hat{\Phi}_{2}, \mathrm{BR} \sim \mathrm{CR} \sim \mathrm{PF}$ with no financing

- In $\hat{\Omega}, \mathrm{BR} \sim \mathrm{CR} \succ \mathrm{PF}$ with financing and $\bar{a}$ under $\mathrm{CR}$, no financing under PF

- In $\hat{\Gamma}, \mathrm{BR} \sim \mathrm{PF} \succ \mathrm{CR}$ with no financing under $\mathrm{PF}$, financing with $\bar{a}$ under $\mathrm{CR}$ 